\title{
Molecular Identification and Characterization of the Biosurfactant Produced by Pseudomonas aeruginosa-PSPA15 from the Oil Contaminated Soil
}

\author{
P. Saminathan ${ }^{1} *$ and P. Rajendran ${ }^{2}$ \\ ${ }^{1}$ Research Scholar, Department of Microbiology, Karpagam University, \\ Coimbatore- 641021, Tamil Nadu, India \\ ${ }^{2}$ Professor, Department of Microbiology, Sri Ramachandra Medical College, \\ Porur, Chennai, Tamil Nadu, India \\ *Corresponding author
}

\begin{tabular}{|c|c|}
\hline & A B S T R A C T \\
\hline Keywords & \multirow{4}{*}{$\begin{array}{l}\text { Oil contaminating in the soil will lead to serious pollution problems. } \\
\text { Bioremediation involves the use of organisms to remove pollutants from a } \\
\text { contaminated site. Biosurfactant are structurally diverse compounds mainly } \\
\text { produced by hydrocarbon utilizing microorganisms which makes them } \\
\text { potential candidates for enhancing oil recovery. Pseudomonas aeruginosa } \\
\text { PSPA } 15 \text { strain is isolated from oil contaminated soil. It is screened to } \\
\text { confirm the ability in the biosurfactant production. The surface tension value } \\
\text { is } 26 \mathrm{mNm}^{-1} \text { and the emulsification indices are } 83 \%, 79 \% \text {, and } 77 \% \text { with } \\
\text { petrol, diesel and kerosene respectively. The sequence of the } 16 \text { srRNA and } \\
\text { PSPA } 15 \text { are compared and it shows } 100 \% \text { similarity to Pseudomonas } \\
\text { aeruginosa gene bank. Biocompatibility assay exhibited no cytotoxicity } \\
\text { against VERO cells. HPLC analysis shows retention time of } 4.37 \\
\text { representing the rhamnolipids type of biosurfactant. }\end{array}$} \\
\hline $\begin{array}{l}\text { Oil pollution, } \\
\text { Bioremediation, } \\
\text { Biosurfactant, } \\
\text { Biocompatibility, } \\
\text { High performance } \\
\text { Liquid } \\
\text { chromatography. }\end{array}$ & \\
\hline Article Info & \\
\hline $\begin{array}{l}\text { Accepted: } \\
28 \text { July } 2016 \\
\text { Available Online: } \\
10 \text { August } 2016\end{array}$ & \\
\hline
\end{tabular}

\section{Introduction}

Oil contamination in the soil has been a major threat to the environment because of the poor solubility. Crude oil can be accidentally or deliberately released into the environment leads to serious pollution problems (Trindale et al., 2005). Bioremediation is a waste management technique that involves the use of the organisms to remove or neutralize pollutants from a contaminated site. An alternative and an eco friendly method of remediation technology of environments contaminated with these pollutants is useful to the biosurfactant and biosurfactant-producing microorganisms. Microbial compounds which exhibit particularly high surface activity and emulsifying activity are classified as biosurfactants. These are structurally diverse compounds, mainly produced by hydrocarbon util10ising microorganisms reduce surface and interfacial tensions in both aqueous solutions and hydrocarbon mixtures, which makes them potential 
candidates for enhancing oil recovery (Sarkar et al., 1989, Singer 1985).

As biosurfactants are readily biodegradable and can be produced from the renewable and cheaper substrates, they might be able to replace their chemically synthesized counter parts (Patel and Desai, 1997). Biosurfactants are extracellular macromolecules produced by bacteria, yeast and fungi and in particular by natural and recombinant bacteria when they grown on the different carbon sources. (Raza et al.,2005). Specifically Pseudomonas species is well known for its ability to produce rhamnolipid biosurfactants with potential surface active properties when grown on the different carbon substrates (Tahzibi et al., 2004) and rhamnolipid biosurfactants produced by these species have a great potential for the industrial application and bioremediation.

\section{Materials and Methods}

\section{Isolation and enumeration of bacteria from the samples}

1 gram of oil contaminated soil sample was diluted with $99 \mathrm{ml}$ of sterile distilled water. The sample was kept in the shaker at 200rpm for 24-48 hrs. After incubation, sample was serially diluted from $10^{-1}$ to $10^{-6}$ in sterile distilled water. From the dilutions $0.1 \mathrm{ml}$ was spread over the $20 \mathrm{ml}$ of sterile Nutrient agar and Cetrimide agar at $37^{\circ} \mathrm{C}$ for 24 hrs (Lowbury and Collins 1955).

\section{Identification of the selected isolate by the} conventional and molecular methods

The selected isolate was subjected to the biochemical and molecular assessment for the identification. Gram staining and all the biochemical test were carried out. The identification and phylogenetic relatedness of the isolates were assessed based on the partial 16srRNA gene sequences using the universal primer (Tamura et al., 2007). To identify the unknown bacterial isolates, the 16 srDNA sequences obtained were subjected to the basic local alignment search tool (BLAST) search (Weisburg et al., 1991).

\section{Extraction of the biosurfactants}

The growth and production of the biosurfactants were studied in the screened carbon sources mineral salt media. Erlenmeyer flasks of $1000 \mathrm{ml}$ capacity containing $250 \mathrm{ml}$ of the mineral salt medium with glycerol as the carbon sources were individually inoculated with $5 \mathrm{ml}$ of particular inoculums (Sekar et al., 2010). The flasks were incubated in the rotary shaker incubator at $30^{\circ} \mathrm{C}$ for $24-48 \mathrm{hrs}$. The culture obtained was used for the extraction of the biosurfactants. The culture medium was centrifuged at $350 \mathrm{~g}$ for $20 \mathrm{~min}$ and then the supernatant was adjusted to $\mathrm{pH}$ of 2.0 by adding $5 \mathrm{~mol} / \mathrm{H}_{2} \mathrm{SO}_{4}$ for the biosurfactant precipitation. The precipitates were extracted in the two volumes of diethely ether/methanol $(1: 1, \mathrm{v} / \mathrm{v}) \quad$ mixture. Evaporation of the solvent yielded biosurfactants (Zhang et al., 2005)

\section{Characterization of biosurfactants}

\section{Surface Tension Measurement (Tadros 2005)}

Surface tension of the biosurfactant containing broth was measured using a drop weight method. Measurements were done in the triplicate.

Surface tension $(\mathrm{ST})=\mathrm{mg} / 3.8 \mathrm{rNm}^{-1}$

Where $\mathrm{m}=$ mass of one drop of the liquid

$\mathrm{g}=$ acceleration due to gravity

$r=$ radius of the capillary tube. 
To determine the ST, mass of the medium has to be calculated by simply weighing the drop of medium. Mass of one drop of the medium;

Where $\mathrm{m}=\mathrm{W}_{2}-\mathrm{W}_{1} /$ Total droplet

W2- Weight of the sample with beaker

W1- Weight of the empty beaker

\section{Emulsification Activity measurement (Cooper and Goldenberg 1987)}

Biosurfactants have the ability to emulsify various hydrocarbons. The emulsifying property of the biosurfactant was carried out with petrol, diesel and kerosene. The emulsification index on the hydrocarbons was calculated by the standard method.

E24 $=$ (Height of the emulsified layer/Total height of the hydrocarbon) x 100 .

\section{Chemical analysis of Biosurfactants (Sawhney and Singh 2000)}

\section{Analysis of Amino acids}

\section{Ninhydrin Test}

It is a general test for all amino acids. 2-5 drops of ninhydrin solution was added to a small amount of biosurfactants. The tube was mixed well and keep for $5 \mathrm{~min}$ in the boiling water bath and observed the colour formation.

\section{Analysis of Carbohydrate}

\section{Anthrone Test}

A tiny amount of biosurfactant was added to the $2 \mathrm{ml}$ of anthrone reagent and it was thoroughly mixed. Colour changes was observed.

\section{Iodine Test}

4-5 drops of iodine solution was added to a little amount of biosurfactant and it was mixed gently. The colour formation was observed.

\section{Barfoed Test}

$2 \mathrm{ml}$ of Barfoed's reagent was added to the little amount of biosurfactant. The tube was heated in a boiling water bath. The formation of colour and also the time taken for its appearance was noted.

\section{Analysis of Lipids}

\section{Solubility Test}

Small amount of biosurfactant was taken in the three test tubes. Water, alcohol and chloroform were added to the each tubes. Their solubility was tested.

\section{Saponification Test}

$2 \mathrm{ml}$ of $2 \% \mathrm{NaOH}$ solution was added to the small amount of biosurfactant and shaken well. The formation of soap was observed.

\section{Acrolein test for Glycerol}

$1.5 \mathrm{~g}$ of potassium hydrogen sulphate was taken in a test tube and little amount of biosurfactant was added. The added biosurfactant was covered completely by adding more of solid potassium hydrogen sulphate on top of it. The test tube was slowly heated and noted the odor of the fumes evolved from the tube.

\section{Biocompatibility assay (Mosmann 1983)}

The biosurfactant was tested for biocompatibility against the VERO cell lines in 24 well tissue culture plates. VERO cell suspension and biosurfactant were added to each well in triplicate. Cells were incubated at $37^{\circ} \mathrm{C}$ for $24 \mathrm{hrs}$ in an atmosphere of $5 \%$ $\mathrm{CO}_{2}$. Biocompatibility was determined by MTT assay and expressed as $\mathrm{IC}_{50}$ i.e., 
concentration inhibiting 50\% cell growth compared to the untreated cell.

\section{Quantitative analysis of biosurfactant by HPLC}

To investigate whether the obtained biosurfactant included the multiple components or not, it was analyzed by LCMS-2010 EV (SHIMADZU) system (Deziel et al., 1999). The mobile phase consisted of $70 \%$ methanol and $30 \%$ methylene chloride, which was injected into a $20 \mu \mathrm{l}$ in $\mathrm{C} 18(250 \mathrm{~mm} \times 4.6 \mathrm{~mm} \times 5 \mu \mathrm{m})$ reverse phase column isocratically. The injection flow rate was $0.5 \mathrm{ml} \mathrm{min}-1$ and absorption of the output was detected by the detector (SPD-M20A).

\section{Results and Discussion}

The soil samples were collected from the oil contaminated sites in Chennai, Tamil Nadu. The cultural and morphological traits of bacterial isolates Pseudomonas aeruginosa PSPA15 was studied. The isolate Pseudomonas aeruginosa PSPA15 has shown green coloured colonies on cetrimide agar contain glycerol as carbon source (Fig:1). Physiological and biochemical characters of the Pseudomonas aeruginosa PSPA15 were examined. The biochemical characterization results were provided in the Table 1.

To confirm the identity of isolate PSPA15, PCR parameter were optimized for the maximum amplification of $16 \mathrm{~s}$ ribosomal RNA gene and was identified by the partial sequencing of the PCR amplified 16srRNA gene. The obtained sequences were submitted to the BLAST in order to find a homology with other 16srRNA sequences (Fig :2A,2B).

The strain PSPA15 achieve the saturated growth on the MSM medium within $12 \mathrm{hrs}$ if glycerol was used as carbon source. Biosurfactant was extracted by solvent method and the extracted biosurfactant was found to be turbid and yellowish brown in colour (Fig. 3).

\section{Characterization of biosurfactant}

The surface tension of the extract was lowered to $26 \mathrm{mNm}^{-1}$. The decrease in surface tension indicated the production of surface active compounds. The emulsification activity (E24) was 83,79 and $77 \%$ for petrol, diesel and kerosene respectively. Chemical analysis of biosurfactant was observed and the results were tabulated (Table: 2). The biocompatibility potential for PSPA15 was quantitatively evaluated by MTT assay (Table. 3). The disaccharides analysis using HPLC showed the fraction with retention time 4.37, representing Rha-Rha-C10-C10 dirhamnolipids (Fig:5).

To isolate bacteria beneficial to biotechnology and bioremediation in soil samples from hydrocarbon contaminated soil located in the city of Chennai, Tamil Nadu, India. A high prevalence of Pseudomonas species was found with a high average when compared with the other genera of bacteria isolated from the same samples (Noura et al., 2009). This may be due to the moisture and warmness of the soil. Some species of Pseudomonas have been recently used as a bioremediation which is able to clear the environmental pollution and improve the hygienic measures and partially or completely degrade the Pollutants (Haas and Defago 2005). Pseudomonas sp. form the second largest group of bacteria producing the biosurfactants. Many strains of Pseudomonas have been reported in producing the glycolipids especially 
rhamnolipids. The structural and regulatory genes encoding the rhamnolipids synthesis pathway had been isolated and characterised (Palashpriya Das et al., 2008)

The fermentation of Pseudomonas aeruginosa was first investigated by using a couple of carbon sources. Rhamnolipid production by glycerol is much higher than that of the other substrates including glucose, vegetable oil and liquid paraffin. So, glycerol is the more effective substrate in the production of biosurfactants among the other substrates. This suggested that there is a carbon source preference of the strain for biosurfactant production, which seems to be strain dependent. Most microbial surfactants were substrate specific, solubilizing or emulsifying different hydrocarbons at different rates (Moussa et al., 2014).The fermentation of biosurfactant was carried out using $30 \mathrm{~g} / \mathrm{L}$ glycerol as the sole carbon source (Matsufuji et al., 1997).

The results obtained from the present investigation revealed that the ability of Pseudomonas aeruginosa in producing biosurfactant in MSM containing glycerol. During the growth of Pseudomonas aeruginosa undergoes two distinct types of metabolism; exponential growth linked with amino acid catabolism and stationary growth which is linked with the glucose metabolism. This behaviour is known as diauxic (Hamilton and Dawes 1960). At this transition point, biosurfactant production was initiated. Rhamnolipids are also produced by Pseudomonas aeruginosa in media containing the glycerol as a carbon source (Mulligan and Gibbs 1989; Wagner et al., 1983)
PCR ribotyping relies on polymorphisms within the 16S-23S intergenic spacer regions. A characteristic pattern is obtained and it represents the size variations in the multiple rRNA operons ( Shula et al.,2001). Comparing the sequence of the 16srRNA of the isolate with the sequence in gene bank revealed that PSPA15 showed 100\% similarity to Pseudomonas aeruginosa. The surface tension (ST) values of PSPA15 was $26 \mathrm{mNm}^{-1}$ and the emulsification activity (E24) were 83, 79, 77\% for petrol, diesel and kerosene respectively. It also emulsifying the petrol than diesel and kerosene and it can be detected by Emulsification Index Method. These results indicated that the PSPA15 remained a vital source of microbial metabolites production. Chemically the presence of carbohydrates, lipids were confirmed. That particular carbohydrates were found to be a pentose sugar and the glycerol was absent in the lipid, hence this indicates that the isolated biosurfactant was a glycolipid. Glycolipids containing sugar and lipid component and do not containing glycerol. Pseudomonas aeruginosa produces glycolipids which act as emulsifiers or surface-active agents; consequently reducing the surface tension of hydrophobic molecules and leading to their breakdown (Femi et al., 2015). According to the ST, E24 and Chemical value, isolates PSPA15 were further studied for the biosurfactant production in a large scale.

Cell culture assays can be used to assess the biocompatibility of a material or extract by using the isolated cells in-vitro. These techniques are useful in evaluating the toxicity or irritancy potential of the materials and chemicals. Cell culture systems may be of the value in testing the biocompatibility of materials before they are introduced. 
Table.1 Biochemical Characterisation of Pseudomonas aeruginosa PSPA15

\begin{tabular}{|l|c|}
\hline Name of the test & Isolates PSPA15 \\
\hline Gram Staining & Gram (-) \\
\hline Motility & Motile \\
\hline Indole & $(-)$ \\
\hline MR/VP & $(-)$ \\
\hline Citrate & $(+)$ \\
\hline TSI & K/K \\
\hline Gelatin Liquefactin & $(+)$ \\
\hline Oxidase & $(+)$ \\
\hline
\end{tabular}

Table.2 Illustrate the ST, E24 and Chemical analysis of Pseudomonas aeruginosa PSPA15:

\begin{tabular}{|c|c|c|c|}
\hline \multicolumn{3}{|c|}{ Name of the test } & Result \\
\hline \multirow{2}{*}{\multicolumn{2}{|c|}{ Surface tension test }} & PSPA15 & $26 \mathrm{mNm}^{-1}$ \\
\hline & & Control & $72 \mathrm{mNm}^{-1}$ \\
\hline \multirow{6}{*}{ Emulsification test } & \multirow{3}{*}{ PSPA15 } & Petrol & $83 \%$ \\
\hline & & Diesel & $79 \%$ \\
\hline & & Kerosene & $77 \%$ \\
\hline & \multirow{3}{*}{ Twenn 80} & Petrol & $85 \%$ \\
\hline & & Diesel & $85 \%$ \\
\hline & & Kerosene & $85 \%$ \\
\hline \multicolumn{3}{|c|}{ Nin hydrin test } & $\begin{array}{l}\text { Absence of Violet blue complex } \\
\text { indicates the absence of Amino } \\
\text { acids }\end{array}$ \\
\hline \multicolumn{3}{|c|}{ Anthrone test } & $\begin{array}{l}\text { Bluish green colour changes } \\
\text { indicates the presence of } \\
\text { carbohydrates }\end{array}$ \\
\hline \multicolumn{3}{|c|}{ Iodine test } & $\begin{array}{l}\text { Absence of blue or reddish brown } \\
\text { complex indicates the presence of } \\
\text { mono/disaccharides. }\end{array}$ \\
\hline \multicolumn{3}{|c|}{ Barfoeds test } & $\begin{array}{l}\text { Presence of red precipitate with } 2- \\
5 \text { min indicates the absence of } \\
\text { monosaccharides }\end{array}$ \\
\hline \multicolumn{3}{|c|}{ Solubility test } & $\begin{array}{l}\text { Insoluble in water and soluable in } \\
\text { alcohol and chloroform }\end{array}$ \\
\hline \multicolumn{3}{|c|}{ Saponification test } & $\begin{array}{l}\text { NaoH saponifies the lipid indicated } \\
\text { by the formation of foam }\end{array}$ \\
\hline \multicolumn{3}{|c|}{ Achrolein test } & $\begin{array}{l}\text { Absence of the pungent smell } \\
\text { indicates the absence of glycerol. }\end{array}$ \\
\hline
\end{tabular}


Table.3 Biocompatibility of the Pseudomonas aeruginosa PSPA15 on VERO cell line.

\begin{tabular}{|c|c|c|c|c|c|c|c|}
\hline \multirow[t]{2}{*}{ S.No } & \multirow{2}{*}{$\begin{array}{c}\text { Concentration } \\
(\mu \mathrm{g} / \mathrm{ml})\end{array}$} & \multirow[t]{2}{*}{ Dilutions } & \multicolumn{4}{|c|}{$\begin{array}{l}\text { Absorbance } \\
\text { (O.D) }\end{array}$} & \multirow{2}{*}{$\begin{array}{c}\text { Cell } \\
\text { Viability } \\
(\%)\end{array}$} \\
\hline & & & I & II & III & Average & \\
\hline 1 & 1000 & Neat & 0.39 & 0.39 & 0.38 & 0.39 & 72.22 \\
\hline 2 & 500 & $1: 1$ & 0.41 & 0.41 & 0.40 & 0.406 & 75.18 \\
\hline 3 & 250 & $1: 2$ & 0.43 & 0.44 & 0.43 & 0.433 & 80.18 \\
\hline 4 & 125 & $1: 4$ & 0.45 & 0.47 & 0.46 & 0.46 & 85.18 \\
\hline 5 & 62.5 & $1: 8$ & 0.48 & 0.48 & 0.48 & 0.48 & 88.88 \\
\hline 6 & 31.2 & $1: 16$ & 0.50 & 0.51 & 0.49 & 0.50 & 92.59 \\
\hline 7 & 15.6 & $1: 32$ & 0.51 & 0.52 & 0.51 & 0.513 & 95.00 \\
\hline 8 & 7.8 & $1: 64$ & 0.52 & 0.53 & 0.53 & 0.526 & 97.40 \\
\hline 9 & Cell control & - & 0.54 & 0.54 & 0.54 & 054 & 100 \\
\hline
\end{tabular}

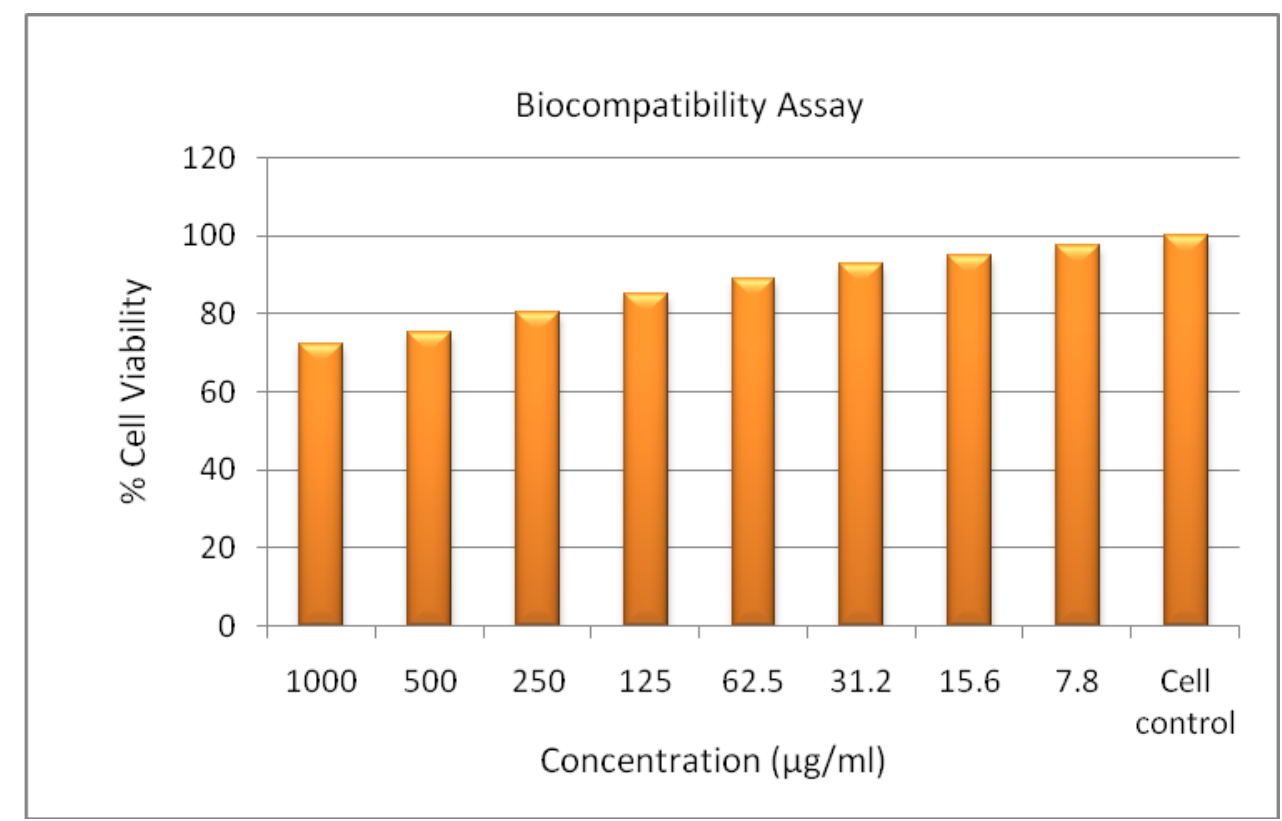

Fig.1 Pseudomonas aeruginosa PSPA15 - growth on Cetrimide Agar GROWTH ON CETRIMIDE AGAR

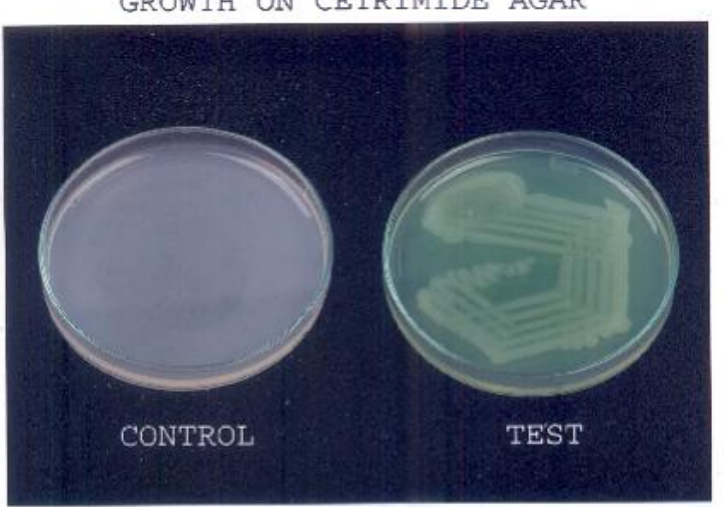


Fig.2a BLAST Analysis Report for Pseudomonas aeruginosa PSPA15

\begin{tabular}{|c|c|c|c|c|c|c|c|c|c|c|c|c|c|}
\hline & & Read Lengtl & th (Normal) & Rea & d Length & Q16) & & lead Le & ngth & Q20) & \multicolumn{3}{|c|}{ GC Content } \\
\hline \multicolumn{3}{|c|}{ 5t_contig_l } & 1408 & \multicolumn{3}{|c|}{1248} & \multicolumn{4}{|c|}{1248} & \multicolumn{3}{|c|}{54.19034090909091} \\
\hline \multicolumn{3}{|r|}{$54 \mathrm{~F}$} & 1168 & \multicolumn{3}{|c|}{1111} & \multicolumn{4}{|c|}{1103} & \multicolumn{3}{|c|}{53.51027397260274} \\
\hline \multicolumn{3}{|r|}{54 R } & 716 & \multicolumn{3}{|c|}{714} & \multicolumn{4}{|c|}{714} & \multicolumn{3}{|c|}{53.63128491620112} \\
\hline \multicolumn{2}{|c|}{ Query } & \multicolumn{5}{|c|}{ Subject } & \multicolumn{3}{|c|}{ Score } & \multicolumn{3}{|c|}{ Identities } & \\
\hline Start & End & Description & $\mathrm{AC}$ & Length & Start & End & Bit & Raw & EV & Match & Total & Pct. $(\%)$ & Strand \\
\hline 1 & 1408 & $\begin{array}{l}\text { Pseudomonas aeruginosa strain } \\
\text { VSS6 } 16 S \text { nbosomal RNA gene, } \\
\text { partial sequence }\end{array}$ & KJ528948.1 & 1498 & 1424 & 17 & 2601 & 1408 & 0.0 & 1408 & 1408 & 100 & Plus/Minus \\
\hline 1 & 1408 & $\begin{array}{l}\text { Pseudomonas aeruginosa strain IHB } \\
\text { B } 6863 \text { l6S nibosomal RNA gene, } \\
\text { partial sequence }\end{array}$ & KF668476.1 & 1500 & 1424 & 17 & 2601 & 1408 & 0.0 & 1408 & 1408 & 100 & Plus/Minus \\
\hline 1 & 1408 & $\begin{array}{l}\text { Pseudomonas aeruginosa PA96 } \\
\text { genome }\end{array}$ & CP007224.1 & 6444091 & 701750 & 700343 & 2601 & 1408 & 0.0 & 1408 & 1408 & 100 & Plus/Minus \\
\hline 1 & 1408 & $\begin{array}{l}\text { Pseudomonas aeruginosa strain } \\
\$ 2041016 \mathrm{~S} \text { nbosomal RNA gene, } \\
\text { partial sequence }\end{array}$ & KF956583.1 & 1549 & 1429 & 22 & 2601 & 1408 & 0.0 & 1408 & 1408 & 100 & Plus/Minus \\
\hline 1 & 1408 & $\begin{array}{l}\text { Pseudomonas aeruginosa strain } \\
\text { C1501 } 16 S \text { ribosomal RNA gene, } \\
\text { partial sequence }\end{array}$ & KF976394.1 & 1501 & 1424 & 17 & 2601 & 1408 & 0.0 & 1408 & 1408 & 100 & Plus/Minus \\
\hline 1 & 1408 & $\begin{array}{l}\text { Pseudomonas aeruginosa LESlike4 } \\
\text { sequence }\end{array}$ & CP006985.1 & 6524053 & 700330 & 698923 & 2601 & 1408 & 0.0 & 1408 & 1408 & 100 & Plus/Minus \\
\hline 1 & 1408 & $\begin{array}{l}\text { Pseudomonas aeruginosa LESlikel } \\
\text { sequence }\end{array}$ & CP006984.1 & 6509070 & 700452 & 699045 & 2601 & 1408 & 0.0 & 1408 & 1408 & 100 & Plus/Minus \\
\hline 1 & 1408 & $\begin{array}{l}\text { Pseudomonas aeruginosa LESB65 } \\
\text { sequence }\end{array}$ & CP006983.1 & 6527005 & 5057599 & 5059006 & 2601 & 1408 & 0.0 & 1408 & 1408 & 100 & Plus/Plus \\
\hline 1 & 1408 & $\begin{array}{l}\text { Pseudomonas aeruginosa LES400 } \\
\text { sequence }\end{array}$ & CP006982.1 & 6591121 & 700549 & 699142 & 2601 & 1408 & 0.0 & 1408 & 1408 & 100 & Plus/Minus \\
\hline 1 & 1408 & $\begin{array}{l}\text { Pseudomonas aeruginosa LESlike7 } \\
\text { seouence }\end{array}$ & CP006981.1 & 6467914 & 700757 & 699350 & 2601 & 1408 & 0.0 & 1408 & 1408 & 100 & Plus/Minus \\
\hline
\end{tabular}

Fig.2b Sequence Allignment of Pseudomonas aeruginosa

>141216-34_A01_54_518F

GGGGGAACCTTTTCCGGATTCTGGGCGTAAGCGCGCGTAGGTGGTTCAGCAAGTTGGATGTGAAATCCCCGGGCTCAACCTGGGA ACTGCATCCAAACTCTGAGCTAGAGTACGGTAGAGGGTGGTGGAATTTCCTGTGTAGCGGTGAAATGCGTAGATATAGGAAGGAA CACCAGTGGCGAAGGCGACCACCTGGACTGATACTGACACTGAGGTGCGAAAGCGTGGGGAGCAAACAGGATTAGATACCCTGG TAGTCCACGCCGTAAACGATGTCGACTAGCCGTTGGGATCCTTGAGATCTTAGTGGCGCAGCTAACGCGATAAGTCGACCGCCTG GGGAGTACGGCCGCAAGGTTAAAACTCAAATGAAGACGGGGGCCCGCACAAGCGGTGGAGCATGTGGTTTAATTCGAAGCAACG CGAAGAACCTTACCTGGCCTTGACATGCTGAGAACTTTCCAGAATGGATTGGTGCCTTCGGGAACTCAGACACAGGTGCTGCATG GCTGTCGTCAGCTCGTGTCGTGAGATGTTGGGTTAAGTCCCGTAACGAGCGCAACCCTTGTCCTTAGTTACCAGCACCTCGGGTGG GCACTCTAAGGAGACTGCCGGTGACAAACCGGAGGAAGGTGGGGATGACGTCAAGTCATCATGGCCCTTACGGCCAGGGCTACA CACGTGCTACAATGGTCGGTACAAAGGGTTGCCAAGCCGCGAGGTGGAGCTAATCCCATAAAACCGATCGTAGTCCGGATCGCA GTCTGCAACTCGACTGCGTGAAGTCGGAATCGCTAGTAATCGTGAATCAAAATGTCACGGGTGAATACCTTCCCCGGGCCTTGTA CACACCGCCCCGTCACACCCATGGGGAGTGGGTTTGCTCCCAAAAGTAACTAAGTCTAACCCGCAAGGGGGGGACGGGTTACCCA CGGGAGTTGATTCATGGACTTGGGGTGGAAGTCCTACAGGGGGGTTAACCCCTTAAAAAACACCCCCCCCTACCCCCCCCCTTCCT TTACCAC

>141216-34_C01_54_800R

GGGGCTCTTTCGCACTCAGTGTCAGTATCAGTCCAGGTGGTCGCCTTCGCCACTGGTGTTCCTTCCTATATCTACGCATTTCACCGC TACACAGGAAATTCCACCACCCTCTACCGTACTCTAGCTCAGTAGTTTTGGATGCAGTTCCCAGGTTGAGCCCGGGGATTTCACAT CCAACTTGCTGAACCACCTACGCGCGCTTTACGCCCAGTAATTCCGATTAACGCTTGCACCCTTCGTATTACCGCGGCTGCTGGCA CGAAGTTAGCCGGTGCTTATTCTGTTGGTAACGTCAAAACAGCAAGGTATTAACTTACTGCCCTTCCTCCCAACTTAAAGTGCTTT ACAATCCGAAGACCTTCTTCACACACGCGGCATGGCTGGATCAGGCTTTCGCCCATTGTCCAATATTCCCCACTGCTGCCTCCCGT AGGAGTCTGGACCGTGTCTCAGTTCCAGTGTGACTGATCATCCTCTCAGACCAGTTACGGATCGTCGCCTTGGTAGGCCTTTACCC CACCAACTAGCTAATCCGACCTAGGCTCATCTGATAGCGTGAGGTCCGAAGATCCCCCACTTTCTCCCTCAGGACGTATGCGGTAT TAGCGCCCGTTTCCGGACGTTATCCCCCACTACCAGGCAGATTCCTAGGCATTACTCACCCGTCCGCCGCTGAATCCAGGAGCAAG CTCCCTTCATCCGCTCGACTTGCATGTGTTAGGCCTGCCGCCAGCGTTCAATCTGAGCGGGTTAAAACTCCTAAAAAACCCCCCCC CAACCCAAATCCCC

The strain PSPA15 was identified as Pseudomonas aeruginosa by 16srRNA sequencing and had a 100\% similarity with the BLAST analysis. 
Fig.3 Fermentation broth showed the production of Biosurfactant extracted from the Pseudomonas aeruginosa PSPA15

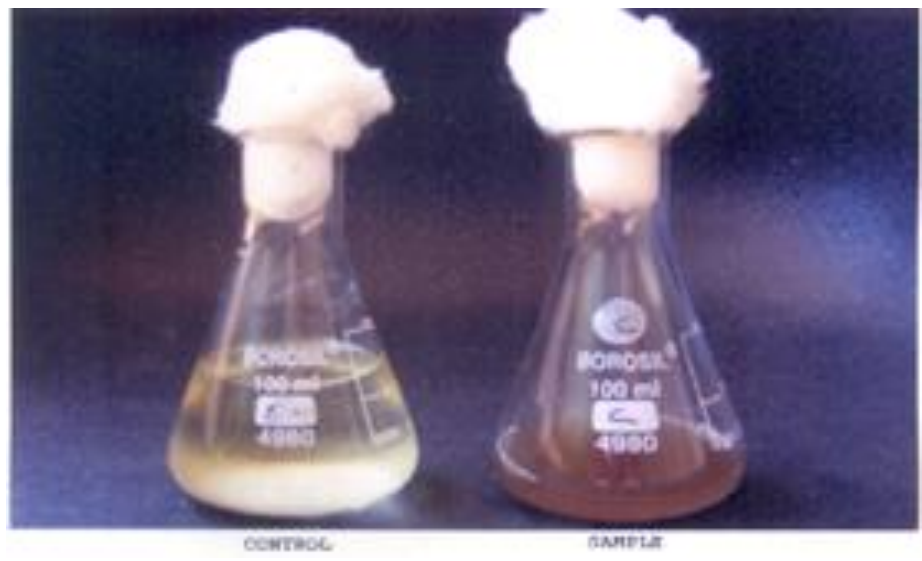

Fig.4 Biocompatibility of the Pseudomonas aeruginosa PSPA15 on VERO cell line

Normal VERO Cell line

Toxicity- $1000 \mu \mathrm{g} / \mathrm{ml}$

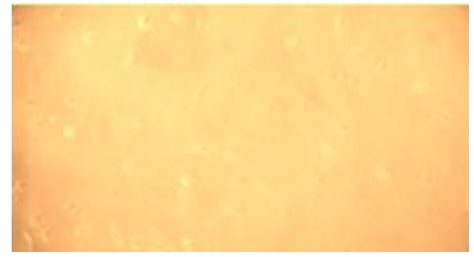

Toxicity- $250 \mu \mathrm{g} / \mathrm{ml}$

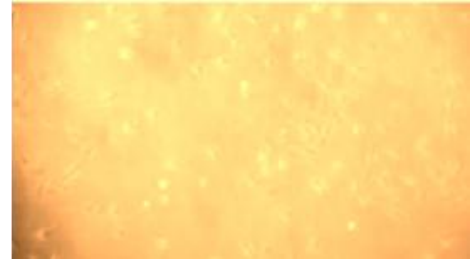

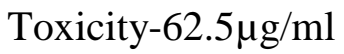

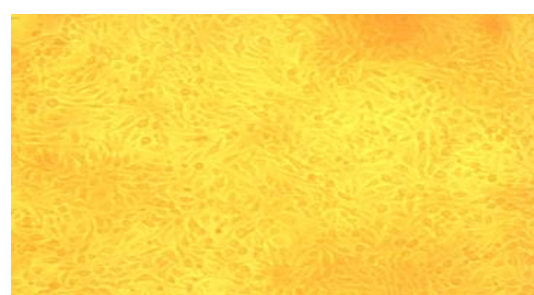

Toxicity-500 $\mu \mathrm{g} / \mathrm{ml}$

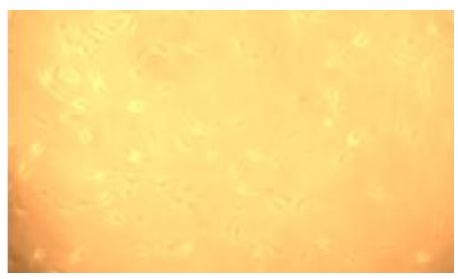

Toxicity- $125 \mu \mathrm{g} / \mathrm{ml}$

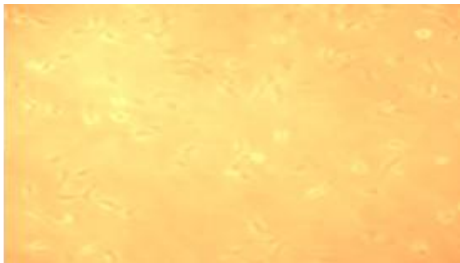

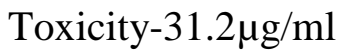
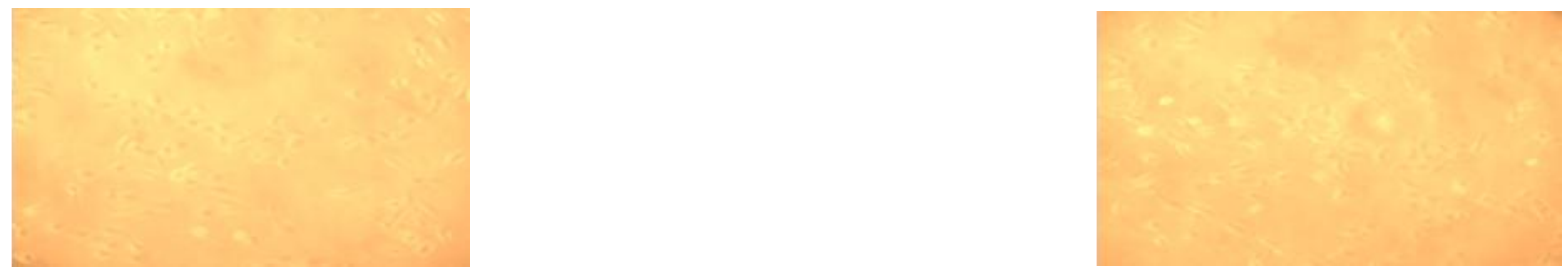
Fig.5 A-HPLC Chromatogram of biosurfactant produced by Pseudomonas aeruginosa PSPA15

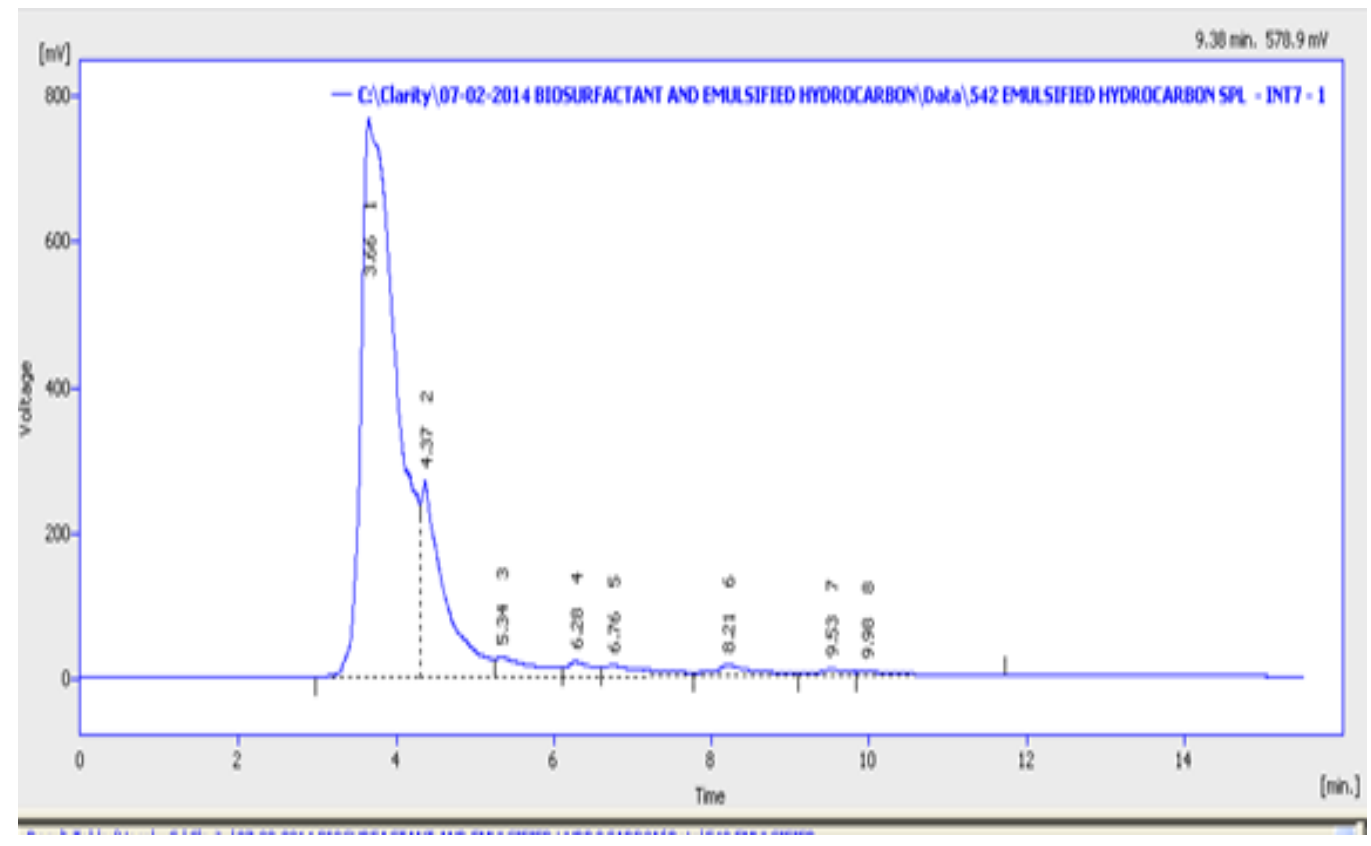

Fig.5 B-HPLC Chromatogram for Standard Rh0-C10-C10 and Rha- Rha C10-C10

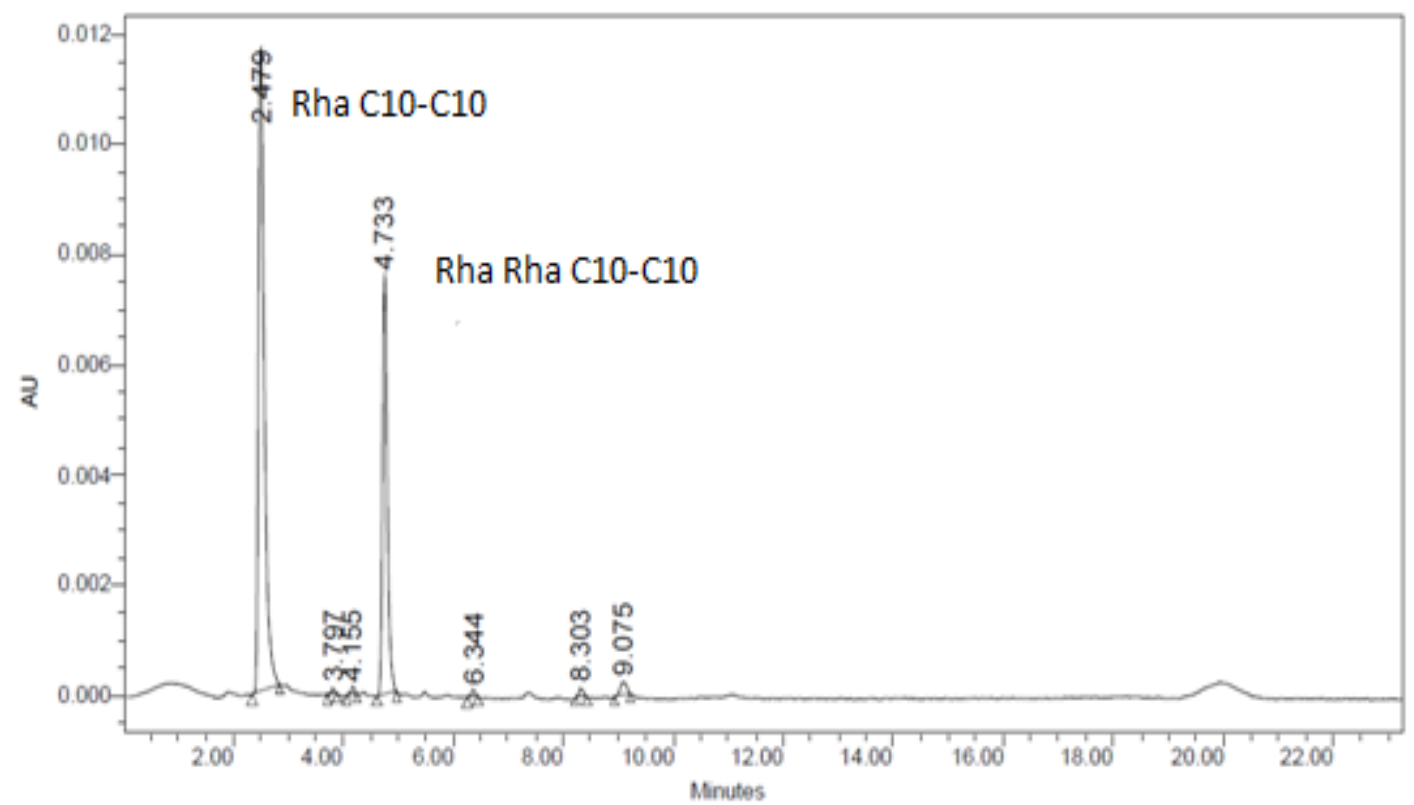

They provide an excellent way to screen the materials prior to in-vivo tests. The MTT assay is a colorimetric method that measures the reduction of yellow 3-(4,5-dimethylthiazol-2-yl)-2,5-diphenyl tetrazolium bromide by mitochondrial succinate dehydrogenase. Because the cellular reduction is only catalyzed by the living cells, it is possible to quantify the percentage of living cells in the solutions. Biosurfactants are biocompatible in nature (Rosenberg et al., 1999) which means 
VERO cells were well tolerated against the biosurfactant which were extracted from the PSPA15 (72.22 to $97.40 \%)$. These when interact with the Cells do not change bioactivity of the VERO cell line. This results are similar to the report of Thanomsub et al., (2007) showed that the biosurfactant, RL-a and RL-b from Pseudomonas aeruginosa B189 had no effect on the normal cell line (VERO) at concentration upto $50 \mu \mathrm{gmL}^{-1}$.

HPLC is an analytical technique for the separation and determination of organic and inorganic solutes in any samples especially biological, pharmaceutical, food, environmental, industrial, etc., (Hencock 1990). HPLC method is one of the suitable methods developed to quantify the rhamnolipids in a bacterial biosurfactant mixture. HPLC analysis showed the fraction with the retention time of 4.37 representing Rha - Rha - C10- C10 which confirmed the structure of dirhamnolipid.

Rha $\mathrm{C} 10-\mathrm{C} 10$ and Rha-Rha $\mathrm{C} 10-\mathrm{C} 10$ are the two rhamnolipids produced from the $P$ aeruginosa PAVIJ strain with higher concentration of Rha Rha C10-C10. Among the four carbon treatments palm oil treatment proved best with a high production of both the rhamnolipids, where LRhamnosyl-L-rhamnosyl-b-hydroxydecanoyl-bhydroxydecanoate and Lrhamnosyl-b-hydroxydecanoyl-b-

hydroxydecanoate, referred to as rhamnolipid 1 and 2, respectively (Rha C10C10 and Rha-Rha C10-C10) are the principal glycolipids produced by $P$. aeruginosa (Vijaya et al., 2014)

In conclusion, Pseudomonas aeruginosa PSPA15 was isolated from the oil contaminated soil in Chennai. The biosurfactant producing ability was determined using the qualitative surface tension and emulsification index techniques. The presence of carbohydrates, lipids were confirmed and the glycerol was absent, hence this indicated that the biosurfactant was a glycolipid. The biosurfactant was non toxic to normal cells and HPLC retention time 4.14 representing glycolipid type of rhamnolipids. New production strain PSPA15 is now available, the economic obstacle of biosurfactants may eventually be eased. Further, the strain PSPA15 will be tested against their efficacy on oil remediation and suitable for using in oil fields such as soil washing, Microbial enhanced oil recovery, removal of heavy metal pollution.

\section{References}

Cooper D, Goldenberg B.1987. Surface active agents from 2 Bacillus species. Appl. Environ. Microbiol; 53(2): 224229,

Deziel E, Lepine F, Dennie D, Boismenu D, Mamer OA, et al. 1999. Liquid chromatography/mass spectrometry analysis of mixtures of Rhamnolipids produced by Pseudomonas aeruginosa strain 57RP grown on mannitol or naphthalene. Biochim Biophys Acta 1440: 244-252.

Femi-Ola, T. O., Oluwole, O. A., Olowomofe, T. O. and Yakubu, H.2015. Isolation and Screening of Biosurfactant- Producing bacteria from soil contaminated with Domestic waste water .British Journal of Environmental Sciences Vol.3, No.1, pp.58-63.

Haas, D. and G.Defago. 2005. Biological control of Soil-borne pathogens by Pseudomonas fluorescens. Nature Rev. Microbiol., 3:307-319.

Hamilton,W.A and Dawes,E.A.1960. The nature of the diauxic effect with glucose and Organic acids in $P$. aeruginosa, 
Proc.Biochem.soc.Biochem.J.76; 70.

Hencock.W.S.1990. High performance Liquid chromatography in Biotechnology. Wiley-Inter science, New Jersey, U.S.A.

Lowbury, E.J.L., and A.G.Collins. 1955. The use of a new Cetrimide product in a selective medium for Pseudomonas aeruginosa. J.Clin.Pathol.8:47.

Matsufuji, M., Nakata, K., Yoshimoto,A. 1997. High production of Rhamnolipids by Pseudomonas aeruginosa growing on ethanol. Biotechnology letters, 19: 1213-1215.

Mosmann T .1983. Rapid colorimetric assay for cellular growth and survival: application to proliferation and cytotoxicity J.Immunol.Methods 65: 55-63

Moussa, T. A. A. M. S. Mohamed and N. Samak. 2014. Production and characterization of Di-Rhamnolipid produced by Pseudomonas aeruginosa TMN. Brazilian Journal of Chemical Engineering. Vol. 31, No. 04, pp. 867 -880 .

Mulligan,C.N and Gibbs,B.F.1989. Correlation of nitrogen metabolism in 15 biosurfactant production by $P$. aeruginosa Appl,Environ, MicrobiaL. 55:3016-3019.

Noura K.M. Salih, N.H. Jusuf, A.A. Hamid and W.M.W.Yusoff.2009.High prevalence of Pseudomonas species in soil samples from Ternate IslandIndonesia. Pakistan Journal of Biological Sciences 12(14):10361040.

Palashpriya Das, Soumen Mukherjee and Ramakrishna Sen. 2008. Genetic regulation of the Biosynthesis of microbial surfactants : An over view. Biotechnology and Genetic engineering reviewa-Vol:25,165-186.

Patel,R.M. and A.J. Desai.1997. Biosurfuctant production by
Pseudomonas aeruginosa GS3 by molasses. Lett . Appl. Microbiol., 25, 91-94.

Raza, Z.A., M .S. Khan, Z .M. Khalid and A Rehman.2005.Production of Biosurfectant Using Different Hydrocarbons by Pseudomonas aeruginosa EBN-8 Mutant. Naturforsch,61C, 87-94.

Rosenberg E, Mitchell R.1986. Microbial surfacatants. Crit Rev Biotechnol 3: $109-132$

Sarkar, A.K., J.C.Goursand, N.M.Sharma, and G.Georgiou.1989. A Critical evaluation of MEOR Process. In situ 13:207-238.

Sawhney, S. K., and R. Singh. 2000. Introductory Practical Biochemistry. Narosa

Publishing House. India, 1: 16: 17.

Sekar,K.V. Sarita kumar, A.Nagasathya, S.Palanivel, and Subramanyam Nambaru. 2010. Effective biosurfactant production by Pseudomonas aeruginosa and its efficacy on different oils. JALRBVol(1): 40-44.

Shula L. Dawson, John C. Fry, Brain N.Dancer.2001. A Comparative evaluation of five typing techniques for determining the diversity of fluorescent Pseudomonas. Cardiff university, P.O .box 915, Cardiff,CF10 3TL,UK.

Singer, M. 1985.Microbial biosurfactants. Microbes oil Recovery 1: 19-38.

Tadros T. 2005.Adsorption of surfactants at the air/liquid and liquid/liquid interfaces. In. Applied surfactants: Principles \& Applications. Weinheim: Wiley VCH: 81-82.

Tahzibi, A., F. Kamal and M.M. Assadi.2004. Improved production of rhamnolipds by a Pseudomonas aeruginosa mutant. Iran. Biomed. J., 8, 25-31. 
Tamura, K., J. Dudley, M. Nei, S. Kumar. 2007. Molecular Biology and Evolution, 24, 1596-1599.

Thanomsub, B.,W, Pumeechockchai, A, Limtrakul, P, Arunrattiyakorn, W, Petchleelaha, T. Nitoda and H.Kanzaki. 2007. Chemical structures and biological activities of rhamnolipids produced by Pseudomonas aeruginosa B189 isolated from milk factory waste. Bioresour.Technol. 98:1149-1153.

Trindale PVO, Sobral LG, RIZZO ACL, Leite SGF, Soriano AV. 2005.Bioremediation of a weathered and recently oil-contaminated soils from Brazil: a comparison study. Chemosphere, 58: 515-522.

Vijaya B, Jayalakshmi NR and Manjunath K.2014.Isolation and partial characterisation of biosurfactant produced by Pseudomonas aeruginosa
PAVIJ from contaminated soil. Research journal of pharmaceutical, biological and chemical sciences, 5(2);881-895.

Wagner,F.,Bock,H.,Kretschmer,A.,Lang,S.a nd Syldatk,C.1983.Production and chemical characterisation of surfactants from Rhodococcus erythropolis and Pseudomonas spp. MUB grown on hydrocarbon .P.55-60.

Weisburg W.G., Barns S.M., Pelletier D.A., and Lane D.J. 1991. 16s ribosomal DNA amplification for phytogenetic study.J. Bacteriol.173,697-703, Shula L. Dawson, John C.Fry, Brain N.Dancer.2001.

Zhang Guo-liang, WU Yue-ting, Qian Xinping, Meng Qin.2005. Biodegradation of crude oil by Pseudomonas aeruginosa in the presence of Rhamnolipids.. Journal of Zhejiang University science 6 B (8): 725-730.

\section{How to cite this article:}

Saminathan, P., and Rajendran, P. 2016. Molecular Identification and Characterization of the Biosurfactant Produced by Pseudomonas aeruginosa-PSPA15 from the Oil Contaminated Soil. Int.J.Curr.Microbiol.App.Sci. 5(8): 708-720. doi: http://dx.doi.org/10.20546/ijcmas.2016.508.080 